\title{
Coerced addiction treatment: Client perspectives and the implications of their neglect
}

\author{
Karen A Urbanoski
}

\begin{abstract}
Recent work has criticized the evidence base for the effectiveness of addiction treatment under social controls and coercion, suggesting that the development of sound policies and treatment practices has been hampered by numerous limitations of the research conducted to date. Implicit assumptions of the effectiveness of coerced treatment are evident in the organization and evolution of treatment, legal, and social service systems, as well as in related legislative practices. This review builds upon previous work by focusing in greater detail on the potential value of incorporating client perspectives on coercion and the implications for interpreting and applying existing research findings. Reviewing the existing empirical and theoretical literature, a case is made for greater accuracy in representing coercive experiences and events in research, so as to better align the measured concepts with actual processes of treatment entry and admission. Attention is given to studies of the effectiveness of treatment under social controls or pressures, the connections to coercion and decision-making, and theoretical perspectives on motivation and behaviour change, including Self-Determination Theory in particular. This synthesis of the available research on coerced addiction treatment suggests that it remains largely unclear to what extent many of the commonly employed methods for getting people into treatment may be detrimental to the treatment process and longer-term outcomes. The impact of coercion upon individual clients, treatment systems, and population health has not been adequately dealt with by addiction researchers to date.
\end{abstract}

\section{Review}

In a recent review, Wild outlined a comprehensive criticism of the evidence base for the effectiveness of treatment under social controls and coercion, suggesting that the development of sound policies and treatment practices has been hampered by numerous limitations of the research conducted to date [1]. As limitations, he highlighted the focus on non-empirical arguments defending or denouncing the use of coercive strategies; the prioritization of legal strategies over other forms of pressure; lack of recognition of the heterogeneity in the implementation of coercive strategies; the neglect of potential iatrogenic effects to individuals, programs, and the system as a whole; and exclusion of stakeholder (i.e., client and service provider) perspectives on coercion. These arguments lay in distinct contrast to an apparently growing consensus that "coercion works" and is a viable strategy for promoting treatment participation [2-4].

\footnotetext{
*Correspondence: kurbanoski@partners.org

${ }^{1}$ Centre for Addiction and Mental Health, 33 Russell St. Toronto, ON, M5S 2S1, Canada

Full list of author information is available at the end of the article
}

This review builds upon the previous work of Wild and other researchers [1,5-7], focusing in greater detail on the potential value of incorporating client perspectives on coercion and considering the implications of their neglect for interpreting and applying existing research findings. It is argued that the evidence base supporting coerced addiction treatment remains weak, and that much could be gained by a revision of the coercion construct, including both expansion of its purview and better specification of the domains involved. Reviewing the existing empirical and theoretical literature, a case is made for greater accuracy in representing coercive experiences and events in research, so as to better align the measured concepts with actual processes of treatment entry and admission. Using a more thoughtful approach toward studying coercion, a more meaningful and consistent set of findings may arise than what has been possible to glean from research to date.

Questions of the effectiveness of using coercive strategies to promote, encourage or force people to enter addiction treatment are highly relevant to present-day treatment systems. Implicit assumptions of the effective- 
ness of treatment under such circumstances are evident in the organization and evolution of treatment, legal, and social service systems, as well as in related legislative practices. In 2006 in the US, a system-wide estimate of $38 \%$ of admissions to publicly-funded addiction treatment programs were referred by the criminal justice system [8]. In 2008-09 in Ontario, Canada's most populous province, $22 \%$ of those in specialized, public treatment reported a condition attached to treatment entry, including treatment as a condition of probation or parole, child custody, receipt of social assistance, continued school attendance or family contact [9]. Just over $8 \%$ reported being referred by the legal system, with a similar proportion referred by friends or family.

Formalized mechanisms for treatment referral and collaboration with the legal system continue to evolve and expand, exemplified by mandatory programs for license reinstatement following convictions for impaired driving and an ever-expanding litany of drug treatment and other problem-solving courts. Growth of workplace alcohol and drug treatment programs contributed to system expansion throughout the 1980s [10], while the role of substance abuse as a barrier to employment and economic self-sufficiency figured largely into debates over welfare reform in North America in the 1990s [11-13]. Within the past decade in Canada, legislation and policies have allowed for the expansion of drug treatment courts across the country [14], as well as for a civil commitment approach towards treatment for adolescents in the province of Alberta [15] and making financial benefits contingent upon treatment participation for some recipients of social assistance in Ontario [16].

Against this backdrop, the sections that follow provide a critical review of the existing body of empirical and theoretical work on coercion, with attention to the conceptual shortcomings of typical definitions and study designs. Implications for future research design and measurement, and for local treatment practices and system policies, are considered.

\section{Search strategy}

This review involved a search of the English-language academic and evaluation literature pertaining to social pressures and coercion to enter addiction treatment. Electronic databases, including PsycInfo, Pubmed/Medline, and the Campbell and Cochrane Collaborations, were searched for the following keywords: substance abuse treatment; perceived coercion; mandates or pressure; compulsory or forced treatment; motivation, readiness to change, or treatment readiness; selfdetermination or autonomy; and outcomes. Additional searches were made of publication and library catalogues of the author's home institutions (the Centre for Addiction and Mental Health and the University of Toronto) and other substance policy and research organizations, including the Canadian Centre on Substance Abuse, Substance Abuse and Mental Health Services Administration, National Institutes for Health, and the European Monitoring Centre on Drugs and Drug Addiction. Only original empirical and review articles were reviewed, excluding anecdotal and opinion pieces. Studies focusing on the use of coercive strategies throughout treatment as opposed to at treatment admission were also excluded, as they are out of the scope of the present review. This includes studies of the effectiveness of applying sanctions and rewards throughout treatment, and the impact of legal or other third-party monitoring and surveillance of the treatment process. Although the research strategy was thorough, the focus on English-language literature places some restrictions on the generalizability of the content. Specifically, the majority of studies were conducted in the US, with smaller numbers from Canada, Australia and the UK.

\section{Social controls versus coercion: drawing the distinction}

As noted by Wild [1], most research to date has defined coerced treatment in terms of referral source or the presence of monitoring conditions or reinforcements, neglecting the implications for client motivation, interest, or intent in pursuing treatment. Research has also largely restricted its focus to pressures or mandates administered by legal authorities, downplaying those mitigated by other social agents [1]. However, a variety of non-legal governmental and other institutions also play an important role in encouraging or mandating treatment entry, as do informal social networks.

Wild provides a helpful distinction between coerced treatment and treatment under social controls [1]. The term coercion is reserved to describe situations in which clients perceive a lack of control over the decision to enter treatment. In other words, coerced treatment refers to that which is perceived as an imposition and an infringement on autonomy, regardless of the agent or source. This is distinguished from treatment under social controls, which refer to the wide range of mandates and pressures that are objectively applied to ensure or encourage treatment entry, but do not explicit account for client perceptions or assigned meanings. These have been classified broadly in terms of their source. Legal pressures include civil commitment, court-ordered treatment, and diversion-to-treatment programs, such as drug treatment courts. Formal non-legal pressures are those mitigated by non-legal institutions or systems, including mandatory treatment referrals by employers, schools, children's aid or social assistance programs. Informal social pressures refer to forms of interpersonal persuasion, including threats and ultimatums by friends and family. Similar distinctions between coercion and man- 
dates or pressures have been recommended elsewhere [17-19].

Both conceptually and empirically, the constructs of social controls and coercion are related. Pressures and mandates from legal, other formal, and informal sources have all been linked with greater perceived coercion [20]. Similarly, legal problems and mandates from legal authorities, employers, and social services are associated with lower autonomous motivation and higher controlled motivation for treatment [21]. The role of informal social network pressures in experiences of coercion is more complex. While informal pressures to quit or reduce substance use and/or to enter treatment are associated with greater controlled motivation [21,22], social network opposition to continued substance use has also been associated with greater autonomous motivation for abstinence [23]. Acting in accordance with the norms and expectations of one's social network may support motivational processes in other ways (e.g., via supporting a need for social relatedness), such that clients may not necessarily experience pressures from this source as threatening to their autonomy.

Despite these associations, there is ample empirical evidence supporting the lack of a direct, or one-to-one, correspondence between objective pressure strategies and perceptions of coercion [1]. Legal mandates are not uniformly reported as coercive, or even necessarily perceived as a deciding factor in entering treatment [24-26]. Similarly, treatment that is not legally mandated appears to nonetheless often involve the avoidance of negative external contingencies on the part of clients [27]. In a study of clients entering outpatient counselling, one-third of those who were legally mandated and two-thirds of employer mandated clients reported no coercion to enter treatment, while over one-third of self-referred clients reported at least some coercion [20]. In a multivariable analysis of predictors of client interest in and initial level of commitment to treatment, internal motivation, but not the objective presence of pressures from legal, other formal, and informal sources, predicted more positive attitudes toward treatment [21]. That is, the measure reflecting the underlying reasons for seeking treatment was a relatively more important predictor of orientation toward treatment than were the objective measures of social events.

These findings highlight that it can not be assumed that external pressures are always tied to the decision to enter addiction treatment $[28,29]$. People seeking treatment are often experiencing multiple internal and external pressures [27,30-32], and the importance of any given one is likely dependent on a host of individual and contextual factors. In addition, many individuals with substance problems initially seek help from services outside the addiction treatment sector, depending on how they and those around them define their problems [33]. In the same way, it is equally problematic to equate self-referrals with voluntarism in seeking treatment. Self-referred clients may nonetheless be avoiding legal or employer sanctions and still perceive a great deal of coercion to enter treatment.

Theoretical work on self-determination further supports the idea that it is perceptions of coercion and threats to autonomy, rather than their objective presence per se, that have implications for motivation and behaviour change. Among social-psychological models for studying health behaviour change, Self-Determination Theory (SDT) is unique in its consideration of autonomy as the central concept [34-36]. It provides a useful framework for studies of coerced treatment by addressing how social events are perceived and how those perceptions affect motivation and behaviour [1]. SDT also distinguishes between autonomous and controlled forms of motivation, based on the reasons for initiating behaviour, its realized adaptive value, and degree of environmental support, among other factors. Briefly, activities enacted out of a sense of personal need and value are autonomously motivated, while those enacted because of external pressures and demands are considered controlled or externally motivated. By linking the degree to which behaviours are integrated and internally valued to their persistence and effectiveness and, in turn, to psychological well-being, SDT provides a rich set of hypotheses concerning the role of autonomy in mechanisms of treatment-assisted recovery. Importantly, by explicitly allowing for differences in the ways that people respond to external events and social contexts, it highlights the inadequacy of considering only external circumstances when addressing coercion.

The distinction between autonomous and controlled forms of motivation represents the major distinguishing factor of SDT from other theories of motivation and behaviour change, such as the stages of change or Transtheoretical Model (TTM) [37]. Differences in the behaviour change process hypothesized by SDT versus TTM stem mainly from the ways that motivation is formed and expected to change over time. The stages of change construct does not account for why some people undertake behaviour change while others do not, which is problematic from the perspective of evaluating the relative effectiveness of social control strategies or coercion to initiate the behaviour change process. An individual who engages in an activity because of perceptions that it is required by others would not be differentiated in level of motivation from another who engages in an activity out of a sense of personal commitment. However, personal valuation of treatment and recovery is possibly an important determinant of positive outcomes in the long-term [34]. 


\section{Effectiveness of treatment under social controls and coercion}

Although conflicting and negative findings are reported with respect to the effectiveness of treatment under legal pressures or mandates $[6,7,38]$, studies have largely found that that legal pressures promote longer retention [26,3943], and that clients who enter treatment under legal pressures show comparable or better short-term treatment responses (e.g., reductions in substance use, criminal activity) to others in treatment [25,39,41,43-49]. These findings are typically interpreted as evidence of the effectiveness of legal pressure strategies. In addition, reviews of studies evaluating mandatory educational or therapeutic interventions for those convicted of impaired driving support their effectiveness in reducing impaired driving recidivism [50,51]. Finally, evaluation work conducted in drug treatment courts has largely concluded that these programs are successful in reducing drug use and criminal activity, at least for the duration of the program [52,53]; although this line of research has fallen under criticism for a number of conceptual and methodological reasons [14,54].

Pressures and mandates from employers have also met with mixed results, including longer retention [55] and a greater likelihood of program completion [56], as well as a lack of differences in retention [57] or substance-related outcomes $[56,58]$ relative to others in treatment. To date, outcome evaluations of those who are mandated to participate in addiction treatment as a condition of receiving social assistance are very limited. Much of the work that has been done has focused on the subpopulation of women and single mothers receiving public aid in the US. These studies generally report positive impacts of treatment on substance use [59-61] and employment outcomes, including job rates and earned wages [13,60-62]. However, these outcomes have not been gauged against equivalent comparison groups of non-mandated or untreated individuals. One study comparing those referred to treatment through the welfare system to selfreferred clients found no difference in rates of treatment completion [63].

Studies of the general population have demonstrated the important role played by informal social networks in pressuring problem drinkers to change their behaviour and/or enter treatment [64-67]. Based on his work, Room has suggested that such pressures are sufficiently common that few people likely enter treatment without being spoken to or pressured by friends or family [68]. Accordingly, in clinical samples, family and friends are among the most common sources of pressures to enter alcohol and drug treatment [27,30-32]. Recognizing the power inherent in social networks, a number of intervention methods involving family and friends and aimed at encouraging or inducing a loved one to enter treatment have been developed and tested [69-73]. These vary in degree of confrontation and involvement of the target individual in negotiating the admission and treatment processes, and to the degree that they have been evaluated. Some evidence has been published suggesting that informal pressures, ranging from encouragements to organized interventions to prompt treatment entry, are associated with higher rates of treatment completion relative to self-referred clients $[69,72]$, as well as a greater likelihood of regular attendance at 12-step meetings and methadone treatment [74]. Further study has linked social network pressures to higher rates of abstinence relative to problem drinkers who are not confronted by their friends and family [70], but lower rates of abstinence relative to others in treatment [75]. The methodological quality of these studies is variable, however. The impact of informal pressures, as they occur and interact with other sources of pressure to enter treatment, on outcomes during and following treatment is largely unknown.

In contrast to the substantial body of research evaluating social controls, studies incorporating client perceptions of coercion into evaluations of addiction treatment are rare. The most commonly used measure of perceived coercion in addiction treatment settings is the MacArthur Perceived Coercion Scale (MPCS), developed by researchers with the MacArthur Research Network to assess the perceptions of psychiatric inpatients of hospital admission processes [76]. The MPCS considers client evaluations of control and choice throughout the admission process at a global level (i.e., without reference to the source or agent of coercion). A newer measure, the Perceived Coercion Scale [18], allows for a source-specific assessment of coercion and has the advantage of being developed specifically for addiction treatment clients; although it has yet to be used in evaluations of treatment process and outcomes. A related line of research involves internal motivational processes, much of it being theorydriven studies of controlled and autonomous motivation for treatment. Empirically, perceived coercion, assessed with the MPCS, is associated with higher controlled motivation and lower autonomous motivation for treatment [21].

Autonomous motivation at admission has been associated with increased session attendance [22,77], longer retention [22,78], and lower rates of in-treatment drug use $[77,79]$. Controlled motivation has been associated with poorer session attendance among clients in methadone maintenance treatment [77], but longer retention in outpatient counselling and therapeutic community settings [22,78]. Among offenders mandated to residential treatment, perceived coercion was unrelated to either treatment completion or re-arrest in the 8 months following treatment [80]. In other studies incorporating postdischarge outcomes, admission levels of autonomous 
motivation have been associated with lower frequency of drinking 9 to 12 months after discharge from alcohol treatment [81], as well as increased smoking cessation rates up to 30 months following a brief intervention $[82,83]$. In addition, randomized trials have substantiated the efficacy of smoking cessation interventions based specifically on promoting and supporting the autonomous motivation of clients $[84,85]$. The context fostered in these trials, guided by SDT, involves providing choice and a meaningful rationale for any specific requests, minimizing pressures and controls, acknowledging clients' feelings, and offering personalized feedback $[86,87]$. This is similar in many ways to the context promoted by Motivational Interviewing (MI) techniques [88], which have also met with success in treating substance use problems [89-91] (see also [92-94] for more explicit comparisons between SDT and MI).

Although the number of studies is relatively small, there is nonetheless growing consensus of the importance, separate from the application of any social controls or pressures, of fostering and supporting autonomous motivation for achieving positive outcomes - a concept that is antithetical to coercion in treatment.

\section{Applying the findings: implications of research practices}

At the outset of this review, it was suggested that much may be gained by a more thoughtful specification of the coercion construct, to better align it with actual experiences of the admission process. The implications of current definitions and research practices for interpretation and application of existing literature is now considered.

Typically, research in this area has employed simple group comparisons, in which clients with a specific, often chart-documented, form of pressure, referral or mandate are compared to others in treatment. However, what constitutes exposure to pressure, resulting in group membership, is not uniform across studies, involving highly variable levels of initial force and ongoing monitoring and surveillance. For instance, a workplace referral may indicate anything from informal suggestions by coworkers or supervisors that treatment be sought voluntarily, to formal conditions of treatment entry carrying the threat of job loss [95]. Once in treatment, urinalyses and ongoing assessments of work performance and treatment compliance may or may not be used as further leverage to promote behaviour change. The lack of consistency in specification of treatment conditions affects not only the mandated or pressured group, but also the comparison groups, which tend to be comprised of a heterogeneous mix of clients who may or may not be pressured or mandated to treatment by other sources. Apparent from the above review of empirical findings, this tendency toward narrow, mutually exclusive groupings is not likely reflective of client experiences of coercion or internal motiva- tional orientations toward treatment. To the extent that all clients are affected by a balance of external and internal forces leading up to treatment entry, studies that use this kind of simple grouping strategy are limited in terms of what they can contribute to debates of effectiveness of coerced treatment.

Another concern with the use of non-equivalent comparison groups relates to illness trajectory and expected outcomes. Evidence suggests that legally mandated clients, in particular, are younger and at an earlier stage in their addiction and treatment careers than others in treatment [32,41,43,46,47,96-98]. This forms the basis of suggestions that coercion is an effective early case-finding strategy, bringing people into treatment before their addiction and other health and social problems become severe $[99,100]$. However, to the extent that these clients are systematically younger and less impaired by their substance use than those in the comparison group, their recovery process, trajectory, and prognosis may be different. Interpretations of differences in outcomes between groups, and the attributions of these differences to treatment, should be made cautiously.

The outcomes typically selected for evaluation have likewise limited what can be gained from this line of research. Evident in the review of empirical work presented here, retention figures heavily into evaluations of treatment under social controls and coercion. In a systematic review conducted 10 years ago, Wild identified retention has been the most commonly examined outcome in evaluations of compulsory treatment [5]. A focus on retention as a measure of outcome reveals implicit assumptions that treatment is both effective and that more is better than less [101]. To be sure, retention is a consistent predictor of positive outcomes across a variety of modalities [102-105]. However, at least for alcohol, it is also the case that brief treatment interventions are among the most effective [106], particularly for those with less severe impairment $[107,108]$. It is further questionable whether formal treatment always serves the best interests of the individual. Estimates suggest that between $7 \%$ to $15 \%$ of those who participate in addiction counselling programs show deterioration in their substance use and psychosocial well-being during or shortly after treatment [109]. Finally, it is also clear from population studies that the majority of individuals who experience substancerelated problems recover without participating in a formal treatment program $[110,111]$, highlighting that it is not a necessary component of the recovery process.

The meaning of retention in mandated and coerced treatment may be particularly limited. At the same time as being associated with better session attendance and longer retention, legal pressures have been linked with poorer cognitive engagement in treatment, described in terms of commitment to the treatment process and 
development of the therapeutic alliance [112]. Descriptions of clients "going through the motions" of treatment without actively engaging or participating in the therapeutic process have been documented as common incidents of non-compliance in both adults and adolescents mandated to treatment $[113,114]$. These findings highlight that, while physical presence in treatment may form part of client engagement, it does not guarantee meaningful participation $[114,115]$. To the extent that session attendance is already compulsory, retention-based measures may be particularly poor proxies for the internalization of treatment content and behaviour change [116]. Here, as with coercion, the personal perceptions of clients with respect to involvement in the therapeutic process are of potentially greater value. The preference for retention-based outcome measures, and interpretation of treatment "effectiveness" based on these measures, raises ethical questions about the intended purpose of mandated and coerced treatment.

Overall, the long-term impacts of treatment under social controls and coercion are largely unknown. There is evidence that initially beneficial outcomes of legally mandated treatment do not persist after the threat of sanctions is lifted $[95,117,118]$ - a finding that is consistent with SDT predictions on the impact of controlled motivation for treatment and recovery [34]. However, outcomes related to quality of life and economic, relational, and psychological well-being in the longer-term have yet to be evaluated. If the targeted outcomes of coerced treatment involve stable recovery from addiction and the alleviation of burden to public health and safety, rather than social control or punishment, then effectiveness has arguably not been adequately demonstrated to date.

\section{The way forward}

The evidence and insights presented here suggest a number of avenues for future research, along with some specific recommendations for methodological approaches toward the study of coerced treatment. Namely, chartdocumented measures, such as mandates and referral source, should be supplemented with broader assessments of perceived limitations to autonomy in decisionmaking around treatment entry. Because clients are often experiencing multiple pressures to seek treatment, there is potential value in assessing pressures or social control strategies across domains (i.e., including all of legal, other formal, and informal sources), and incorporating dimensions of strength or importance in the decision to seek treatment. Note that these approaches are inconsistent with the tendency toward classifying clients into mutually exclusive groups.

In addition, a continued focus on retention to the exclusion of other measures of process and outcome is not likely to produce additional information of value to debates of effectiveness of coercion. To the aim of understanding the treatment process, attendance-based measures should be supplemented with additional measures of cognitive engagement and involvement. To the aim of understanding treatment outcomes, attendance-based measures should be supplemented with broader measures of recovery, including indicators of substance use and related problems, economic and psychological wellbeing, criminal activity and others. Comprehensive models of treatment-assisted recovery, incorporating both intreatment and post-treatment outcomes, are available in the published literature $[119,120]$, and may provide guidance in this area.

More generally, research is needed into social contexts of recovery from addiction problems, including identification of salient elements of treatment and informal support networks that promote or hamper the recovery process. Theoretical work on self-determination suggests that coercion and autonomy play a central role in this process, with consequences for stabilized recovery in the long-term. This and other theoretical work on health behaviour change may provide guidance on the selection of appropriate measures and in outlining the mechanisms through which they influence each other and outcomes. External pressures to enter treatment, broadly defined and qualified in terms of their meaning to clients, as well as perceptions of coercion, development of the therapeutic alliance, and receipt of social supports both within and outside of treatment are all constructs consistent with an SDT framework toward evaluating recovery. Other work that takes a life-course approach toward the study of addiction and treatment careers may also offer guidance in this area [121]. By explicitly incorporating aspects of the social context, including social capital and critical external and internal events, a life-course approach to the study of coerced treatment may help to clarify the relationship between pressures and coercion, as well as the circumstances under which social control strategies are most likely to achieve the desired outcomes.

Reflection on the desired outcomes of treatment under social controls and coercion is needed not only to guide measurement selection in research studies, but also for responsible policy development and service delivery. This includes development of appropriate and ethical treatment interventions, monitoring and surveillance practices, and responses by treatment and other professionals (e.g., legal authorities, employers, and social service providers) to incidents of non-compliance or lapses during recovery. As an example, the abstinence orientation of treatment under legal controls is arguably not reflective of a chronic illness model of addiction, which calls for recognition of the role of relapse and the potential for multiple treatment episodes over the course of recovery 
$[14,122,123]$. Abstinence-based programs with punitive sanctions may not be suitable for all individuals with substance use problems. Those with severe and entrenched disorders may be at a higher risk of failing, thereby incurring additional punishment rather than treatment. More generally, an emphasis on the use of compulsory treatment to the benefit and protection of society over that of the individual may result in the imposition of treatment even when it is found to be ineffective, or over a longer period of time than is strictly necessary for treatment purposes $[124,125]$. It has been suggested that treatment provided in, or mediated by, the legal system may be driven less by client need than by local practices and policies for dealing with drug-using offenders [7]. Attention to these issues is needed to inform policy and practice guidelines around the use of social control strategies, and to ensure that practices align with the intended objectives of treatment.

\section{Conclusions}

The concepts of self-determination and autonomy have not traditionally played a large role in studies of treatment-assisted recovery from addiction problems. Discussions of the role of coercion in addiction treatment have instead tended to centre on public health concerns of addiction, economic productivity, crime and infectious disease $[39,124,126]$. As a result, it remains largely unclear to what extent many of the commonly employed methods for getting people into treatment may be detrimental to the treatment process and, by extension, longer-term outcomes.

The ethical dilemma posed by coerced addiction treatment is complex from a public health perspective. Substance abuse poses real threats to public health and societal well-being, and this provides a strong impetus for government and other formal institutions to intervene in the lives of those with addiction problems. Ethical frameworks for the justification of public health intervention cite factors such as effectiveness and necessity of the measure in promoting and/or protecting the health of the public, and safe-guarding a balance between positive and negative effects of the intervention, as relevant concerns in the debate over whether to infringe upon individual autonomy and liberty $[127,128]$. Applied to the case of coerced addiction treatment, evidence would have to be brought to bear on whether the proposed course of treatment is likely to be successful in alleviating current harm and preventing future harm to the public that stems from the individual's use of substances and whether it is a necessary means to achieve these ends. Once demonstrated, it also needs to be considered whether the benefits outweigh any negative consequences resulting from the infringement of the individual's right to make their own decisions relating to treatment. It is not at all clear that past research has satisfied these conditions. Ethical arguments such as these do not prohibit the legitimacy of using social control strategies or restricting individual rights in the name of public health, but they do offer guidance to those charged with devising and implementing policies in this regard.

It remains to be demonstrated whether the exposure to treatment among coerced clients is ultimately beneficial or harmful in the long-run for the individual and for the public. The arguments presented in this review are not meant to belittle the negative effects of addiction, which is itself highly detrimental to psychological well-being, functioning, and development, nor is it meant to downplay the potential benefits of treatment. However, it is also relevant that formal treatment is only one option for overcoming addiction problems and, as noted earlier, many recover without it or with only brief supports from non-specialized professionals. These considerations are highly relevant in the current context of an increasingly widened net of addiction treatment, in which those who enter treatment under pressures appear to have less severe substance-related problems than those who are not pressured or mandated. The impact of coercion upon individual clients, treatment systems, and population health has not been adequately dealt with by addiction researchers to date.

\section{Competing interests}

The author declares that they have no competing interests.

\section{Authors' contributions}

This work constitutes a portion of the author's doctoral dissertation, conducted at the Dalla Lana School of Public Health, University of Toronto. The author conceived of and conducted all aspects of the review.

\section{Acknowledgements}

The author acknowledges the contributions of Brian Rush, Susan Bondy and Jurgen Rehm in reviewing versions of this work. During the completion of this work, the author received funding support from the Ontario Government Scholarships in Science and Technology program, the CIHR Strategic Training Program in Research in Addictions and Mental Health Policy, and grant funding from the Canadian Institutes of Health Research (PI: T. Cameron Wild). Salary support for CAMH scientists is also provided from the Ontario Ministry of Health and Long Term Care. The views expressed in this document are those of the authors and do not necessarily represent those of Centre for Addiction and Mental Health or the Ministry of Health and Long Term Care.

Author Details

Centre for Addiction and Mental Health, 33 Russell St. Toronto, ON, M5S 2S1, Canada

Received: 5 October 2009 Accepted: 20 June 2010

Published: 20 June 2010

\section{References}

1. Wild TC: Social control and coercion in addiction treatment: Towards evidence-based policy and practice. Addiction 2006, 101:40-49.

2. National Institute of Drug Abuse: Principles of drug abuse treatment for criminal justice populations: a research-based guide. Bethesda, MD National Institutes of Health; 2006

3. Nace EP, Birkmayer F, Sullivan MA, Galanter M, Fromson JA, Frances RJ, Levin FR, Lewis C, Suchinsky RT, Tamerin JS, Westermeyer J: Socially 
sanctioned coercion mechanisms for addiction treatment. American Journal on Addictions 2007, 16:15-23.

4. Sullivan MA, Birkmayer F, Boyarsky BK, Frances RJ, Fromson JA, Galanter M, Levin FR, Lewis C, Nace EP, Suchinsky RT, et al:: Uses of coercion in addiction treatment: Clinical aspects. American Journal on Addictions 2008, 17:36-47.

5. Wild TC, Roberts AB, Cooper EL: Compulsory substance abuse treatment: An overview of recent findings and issues. European Addiction Research 2002, 8:84-93.

6. Klag S, O'Callaghan F, Creed P: The use of legal coercion in the treatment of substance abusers: an overview and critical analysis of thirty years of research. Substance Use and Misuse 2005, 40:1777-1795.

7. Stevens A, Berto D, Heckman W, KerschI V, Oeuvray K, Van Ooyen M, Steffan E, Uchtenhagen A: Quasi-compulsory treatment of drug dependent offenders: An international literature review. Substance Use and Misuse 2005, 40:269-283.

8. SAMHSA: Treatment Episode Data Set (TEDS). Highlights 2006. National Admissions to Substance Abuse Treatment Services. Rockville, MD: DASIS Series: S-40, DHHS Publication No (SMA) $08-43132008$ [http:// www.oas.samhsa.gov/TEDS2k6highlights/toc.cfm]. Accessed 02 August 2008

9. The Drug and Alcohol Information System [http://www.datis.ca]

10. Schmidt L, Weisner C: Developments in alcoholism treatment. In Recent developments in Alcoholism Volume 11. Edited by: Galanter M. New York: Plenum Press; 1993:369-396.

11. Snyder L: Workfare: ten years of pickin' on the poor. In Canadian social policy: issues and perspectives 4th edition. Edited by: Westhues A. Waterloo, ON: Wilfrid Laurier University Press; 2006.

12. Jayakody R, Danziger S, Pollack H: Welfare reform, substance use, and mental health. Journal of Health Politics and Law 2000, 25:623-651.

13. Metsch LR, Pereyra M, Miles CC, McCoy CB: Welfare and work outcomes after substance abuse treatment. Social Service Review 2003, 77:237-254.

14. Werb D, Elliott R, Fischer B, Wood E, Montaner J, Kerr T: Drug treatment courts in Canada: An evidence-based review. HIV/AIDS Policy and Law Review 2007, 12:12-17

15. The Protection of Children Abusing Drugs Program [http:// www.aadac.com/565 1719.asp]

16. Ontario Works Policy Directives [http://www.mcss.gov.on.ca/en/mcss/ programs/social/ow/index.aspx]

17. Polcin DL: Drug and alcohol offenders coerced into treatment: A review of modalities and suggestions for research on social model programs. Substance Use and Misuse 2001, 36:589-608.

18. Klag S, Creed P, O'Callaghan F: Development and initial validation of an instrument to measure perceived coercion to enter treatment for substance abuse. Psychology of Addictive Behaviors 2006, 20:463-470.

19. Longshore D, Prendergast M, Farabee D: Coerced treatment for drugusing criminal offenders. In Drug treatment: what works? Edited by: Bean P, Nemitz T. New York: Routledge; 2004:109-121.

20. Wild TC, Newton-Taylor B, Alletto R: Perceived coercion among clients entering substance abuse treatment: Structural and psychological determinants. Addictive Behaviors 1998, 23:81-95.

21. Wild TC, Cunningham J, Ryan RM: Social pressure, coercion, and client engagement at treatment entry: a self-determination theory perspective. Addictive Behaviors 2006, 31:1858-1872.

22. Ryan RM, Plant RW, O'Malley S: Initial motivations for alcohol treatment: Relations with patient characteristics, treatment involvement, and dropout. Addictive Behaviors 1995, 20:279-297.

23. Downey L, Rosengren DB, Donovan DM: To thine own self be true: Selfconcept and motivation for abstinence among substance abusers. Addictive Behaviors 2000, 25:743-757.

24. Stevens A, Berto D, Frick U, Hunt N, Kerschl V, McSweeney T, Oeuvray K, Puppo I, Santa Maria A, Schaaf S, et al:: The relationship between legal status, perceived pressure and motivation in treatment for drug dependence: Results from a European study of quasi-compulsory treatment. European Addiction Research 2006, 12:197-209.

25. Anglin MD, Brecht ML, Maddahian E: Pre-treatment characteristics and treatment performance of legally coerced versus voluntary methadone maintenance admissions. Criminology 1989, 27:537-557.

26. Vickers-Lahti M, Garfield F, McCusker J, Hindin R, Bigelow C, Love C, Lewis $B$ : The relationship between legal factors and attrition from a residential drug abuse treatment program. Journal of Psychoactive Drugs 1995, 27:17-25.
27. Marlowe DB, Kirby KC, Bonieskie LM, Glass DJ, Dodds LD, Husband SD, Platt JJ, Festinger DS: Assessment of coercive and noncoercive pressures to enter drug abuse treatment. Drug and Alcohol Dependence 1996, 42:77-84.

28. Weisner C, Mertens J, Tam T, Moore C: Factors affecting the initiation of substance abuse treatment in managed care. Addiction 2001, 96:705-716

29. Weisner C, Matzger $\mathrm{H}$ : A prospective study of the factors influencing entry to alcohol and drug treatment. Journal of Behavioral Health Services and Research 2002, 29:126-137.

30. Marlowe DB, Merikle EP, Kirby KC, Festinger DS, McLellan AT: Multidimensional assessment of perceived treatment-entry pressures among substance abusers. Psychology of Addictive Behaviors 2001, 15:97-108.

31. Cunningham J, Sobell LC, Sobell MB, Gaskin J: Alcohol and drug abusers' reasons for seeking treatment. Addictive Behaviors 1994, 19:691-696.

32. Polcin DL, Weisner C: Factors associated with coercion in entering treatment for alcohol problems. Drug and Alcohol Dependence 1999, 54:63-68.

33. Weisner C: The social ecology of alcohol treatment in the United States. In Recent Developments in Alcohol Volume 5. Edited by: Galanter M. New York: Plenum Press; 1987:203-243.

34. Deci EL, Ryan RM: The "what" and "why" of goal pursuits: Human needs and the self-determination of behaviour. Psychological Inquiry 2000, 11:227-268

35. Deci EL, Ryan RM: Handbook of self-determination research. Rochester, NY: University of Rochester Press; 2002

36. Deci EL, Ryan RM: Self-determination theory: a macrotheory of human motivation, development, and health. Canadian Psychology 2008, 49:182-185

37. Prochaska JO, DiClemente CC: Toward a comprehensive model of change. In Treating addictive behaviors: Processes of change Edited by: Miller WR, Heather N. New York: Plenum; 1986:3-27.

38. Longshore D, Teruya C: Treatment motivation in drug users: A theorybased analysis. Drug and Alcohol Dependence 2006, 81:179-188.

39. Leukefeld CG, Tims FM: Compulsory treatment of drug abuse: Research and clinical practice. Rockville, MD: US Department of Health and Human Services; 1988. (NIDA Research Monograph No. 86)

40. Young D: Impacts of perceived legal pressure on retention in drug treatment. Criminal Justice and Behavior 2002, 29:27-55.

41. Brecht ML, Anglin MD, Dylan M: Coerced treatment for methamphetamine abuse: Differential patient characteristics and outcomes. American Journal of Drug and Alcohol Abuse 2005, 31:337-356.

42. Knight K, Hiller ML, Broome KM, Simpson DD: Legal pressure, treatment readiness, and engagement in long-term residential programs. Journal of Offender Rehabilitation 2000, 31:101-115.

43. Copeland J, Maxwell JC: Cannabis treatment outcomes among legally coerced and non-coerced adults. BMC Public Health 2007, 7:111.

44. Collins JJ, Allison M: Legal coercion and retention in drug abuse treatment. Hospital and Community Psychiatry 1983, 34:1145-1149.

45. Brecht ML, Anglin MD, Wang JC: Treatment effectiveness for legally coerced versus voluntary methadone maintenance clients. American Journal of Drug and Alcohol Abuse 1993, 19:89-106.

46. Kelly JF, Finney JW, Moos RH: Substance use disorder patients who are mandated to treatment: Characteristics, treatment process, and 1- and 5-year outcomes. Journal of Substance Abuse Treatment 2005, 28:213-223.

47. Grichting E, Uchtenhagen A, Rehm J: Modes and impact of coercive inpatient treatment for drug-related conditions in Switzerland. European Addiction Research 2002, 8:78-83.

48. Perron $B E$, Bright $C L$ : The influence of legal coercion on dropout from substance abuse treatment: results from a national survey. Drug Alcohol Depend 2008, 92:123-131.

49. Burke AC, Gregoire TK: Substance abuse treatment outcomes for coerced and noncoerced clients. Health and Social Work 2007, 32:7-15.

50. Canada Health: Best practices: treatment and rehabilitation for driving while impaired offenders. Ottawa, ON: Author; 2004.

51. Wells-Parker E, Bangert-Drowns R, McMillen R, Williams M: Final results from a meta-analysis of remedial interventions with drink/drive offenders. Addiction 1995, 90:907-926.

52. Sanford JS, Arrigo BA: Lifting the cover on drug courts: Evaluation findings and policy concerns. International Journal of Offender Therapy and Comparative Criminololgy 2005, 49:239-259. 
53. Belenko S: Research on drug courts: A critical review. 2001 update. New York: National Centre on Addiction and Substance Abuse; 2001.

54. Fischer B: 'Doing good with a vengeance': A critical assessment of the practices, effects and implications of drug treatment courts in North America. Criminal Justice 2003, 3:227-248.

55. Mertens JR, Weisner CM: Predictors of substance abuse treatment retention among women and men in an HMO. Alcoholism: Clinical and Experimental Research 2000, 24:1525-1533.

56. Lawental E, McLellan AT, Grissom GR, Brill P, O'Brien C: Coerced treatment for substance abuse problems detected through workplace urine surveillance: Is it effective? Journal of Substance Abuse 1996, 8:115-128.

57. Slaymaker VJ, Owen PL: Employed men and women substance abusers: job troubles and treatment outcomes. Journal of Substance Abuse Treatment 2006, 31:347-354

58. Freedberg EJ, Johnston WE: Outcome with alcoholics seeking treatment voluntarily or after confrontation by their employer. Journal of Occupational Medicine 1980, 22:83-86.

59. Morgenstern J, Blanchard KA, McCrady BS, McVeigh KH, Morgan TJ, Pandina RJ: Effectiveness of intensive case management for substancedependent women receiving temporary assistance for needy families. American Journal of Public Health 2006, 96:2016-2023.

60. McLellan AT, Gutman M, Lynch K, McKay JR, Ketterlinus R, Morgenstern J, Woolis D: One-year outcomes from the CASAWORKS for Families intervention for substance-abusing women on welfare. Evaluation Review 2003, 27:656-680.

61. Morgenstern J, Neighbors CJ, Kuerbis A, Riordan A, Blanchard KA, McVeigh $\mathrm{KH}$, Morgan TJ, McCrady B: Improving 24-month abstinence and employment outcomes for substance-dependent women receiving temporary assistance for needy families with intensive case management. American Journal of Public Health 2009, 99:328-333.

62. Wickizer TM, Campbell K, Krupski A, Stark K: Employment outcomes among AFDC recipients treated for substance abuse in Washington State. Milbank Quarterly 2000, 78:585-608.

63. Brizer DA, Maslansky R, Galanter M: Treatment retention of patients referred by public assistance to an alcoholism clinic. American Journal of Drug and Alcohol Abuse 1990, 16:259-264.

64. Room R, Bondy S, Ferris J: Determinants of suggestions for alcohol treatment. Addiction 1996, 91:643-655.

65. Room R, Greenfield TK, Weisner C: "People who might have liked you to drink less": Changing responses to drinking by U.S. family members and friends, 1979-1990. Contemporary Drug Problems 1991, 18:573-595.

66. Hasin DS: Treatment/self-help for alcohol-related problems: Relationship to social pressure and alcohol dependence. Journal of Studies on Alcohol 1994, 55:660-666.

67. Room R, Matzger H, Weisner C: Sources of informal pressure on problematic drinkers to cut down or seek treatment. Journal of Substance Use 2004, 9:280-295.

68. Room R: The U.S. general population's experiences of responding to alcohol problems. British Journal of Addiction 1989, 84:1291-1304.

69. Loneck B, Garrett JA, Banks SM: A comparison of the Johnson Intervention with four other methods of referral to outpatient treatment. American Journal of Drug and Alcohol Abuse 1996, 22:233-246.

70. Liepman MR, Nirenburg TD, Begin AM: Evaluation of a program designed to help family and significant others to motivate resistant alcoholics into recovery. American Journal of Drug and Alcohol Abuse 1989, 15:209-221

71. Miller WR, Meyers RJ, Tonigan JS: Engaging the unmotivated in treatment for alcohol problems: A comparison of three strategies for intervention through family members. Journal of Consulting and Clinical Psychology 1999, 67:688-697.

72. Garrett J, Landau-Stanton J, Stanton MD, Stellato-Kabat J, Stellato-Kabat D: ARISE: A method for engaging reluctant alcohol- and drug-dependent individuals in treatment. Albany-Rochester Interventional Sequence for Engagement. Journal of Substance Abuse Treatment 1997, 14:235-248.

73. Meyers RJ, Miller WR, Hill DE, Tonigan JS: Community reinforcement and family training (CRAFT): Engaging unmotivated drug users in treatment. Journal of Substance Abuse 1998, 10:291-308.

74. Gyarmathy VA, Latkin CA: Individual and social factors associated with participation in treatment programs for drug users. Substance Use and Misuse 2008, 43:1865-1881.
75. Loneck B, Garrett JA, Banks SM: The Johnson Intervention and relapse during outpatient treatment. American Journal of Drug and Alcohol Abuse 1996, 22:363-375.

76. Gardner W, Hoge SK, Bennett N, Roth LH, Lidz CW, Monahan J, Mulvey EP: Two scales for measuring patients' perceptions for coercion during mental hospital admission. Behavioral Sciences and the Law 1993, 11:307-321.

77. Zeldman A, Ryan RM, Fiscella K: Motivation, autonomy support, and entity beliefs: Their role in methadone maintenance treatment. Journal of Social and Clinical Psychology 2004, 23:675-696.

78. De Leon G, Melnick G, Kressel D, Jainchill N: Circumstances, motivation, readiness, and suitability (the CMRS scales): Predicting retention in therapeutic community treatment. American Journal of Drug and Alcohol Abuse 1994, 20:495-515.

79. Downey L, Rosengren DB, Donovan DA: Sources of motivation for abstinence: A replication analysis of the Reasons for Quitting Questionnaire. Addictive Behaviors 2001, 26:79-89.

80. Prendergast M, Greenwell L, Farabee D, Hser YI: Influence of Perceived Coercion and Motivation on Treatment Completion and Re-Arrest among Substance-Abusing Offenders. J Behav Health Serv Res 2008.

81. Staines G, Magura S, Rosenblum A, Fong C, Kosanke N, Foote J, Deluca A: Predictors of drinking outcomes among alcoholics. American Journal of Drug and Alcohol Abuse 2003, 29:203-218.

82. Williams GC, Gagne M, Ryan RM, Deci EL: Facilitating autonomous motivation for smoking cessation. Health Psychology 2002, 21:40-50.

83. Curry SJ, Grothaus L, McBride C: Reasons for quitting: Intrinsic and extrinsic motivation for smoking cessation in a population-based sample of smokers. Addictive Behaviors 1997, 22:727-739.

84. Williams GC, McGregor HA, Sharp D, Levesque CS, Kouides RW, Ryan RM, Deci EL: Testing a self-determination theory intervention for motivating tobacco cessation: Supporting autonomy and competence in a clinical trial. Health Psychology 2006, 25:91-101.

85. Williams GC, Cox EM, Kouides RW, Deci EL: Presenting the facts about smoking to adolescents: The effects of an autonomy supportive style. Archives of Pediatrics and Adolescent Medicine 1999, 153:959-964.

86. Ryan RM, Deci EL: A Self-Determination Theory approach to psychotherapy: The motivational basis for effective change. Canadian Psychology 2008, 49:186-193.

87. Deci EL, Eghari H, Patrick BC, Leone DR: Facilitating internalization: The self-determination theory perspective. Journal of Personality 1994 62:119-142.

88. Miller WR, Rollnick S: Motivational interviewing New York: Guilford Press; 2002.

89. Carroll KM, Ball SA, Nich C, Martino S, Frankforter TL, Farentinos C, Kunkel LE, Mikulich-Gilbertson SK, Morgenstern J, Obert JL, et al:: Motivational interviewing to improve treatment engagement and outcome in individuals seeking treatment for substance abuse: A multisite effectiveness study. Drug and Alcohol Dependence 2006, 81:301-312.

90. Burke BL, Arkowitz H, Menchola M: The efficacy of Motivational Interviewing: A meta-analysis of controlled clinical trials. Journal of Clinical and Consulting Psychology 2003, 71:843-861

91. Vasilaki El, Hosier SG, Cox WM: The efficacy of motivational interviewing as a brief intervention for excessive drinking: A meta-analytic review. Alcohol and Alcoholism 2006, 41:328-335.

92. Markland D, Ryan RM, Tobin VJ, Rollnick S: Motivational interviewing and self-determination theory. Journal of Social and Clinical Psychology 2005, 24:811-831.

93. Foote J, DeLuca A, Magura S, Warner A, Grand A, Rosenblum A, Stahl S: A group motivational treatment for chemical dependency. Journal of Substance Abuse Treatment 1999, 17:181-192.

94. Vansteenkiste M, Sheldon KM: There's nothing more practical than a good theory: Integrating motivational interviewing and selfdetermination theory. British Journal of Clinical Psychology 2006, 45:63-82.

95. Weisner C: Coercion in alcohol treatment. In Broadening the Base of Treatment for Alcohol Problems Washington, DC: National Academy Press, Institute of Medicine; 1990.

96. Rush BR, Wild TC: Substance abuse treatment and pressures from the criminal justice system: data from a provincial client monitoring system. Addiction 2003, 98:1119-1128. 
97. Marshall GN, Hser Yl: Characteristics of criminal justice and noncriminal justice clients receiving treatment for substance abuse. Addictive Behaviors 2002, 27:179-192.

98. Polcin DL, Beattie M: Relationship and institutional pressure to enter treatment: Differences by demographics, problem severity, and motivation. Journal of Studies on Alcohol and Drugs 2007, 68:428-436.

99. Marlowe DB, Patapis NS, DeMatteo DS: Amenability to treatment of drug offenders. Federal Probation 2003, 67:40-46.

100. Sowers WE, Daley DC: Compulsory treatment of substance use disorders. Criminal Behavior and Mental Health 1993, 3:403-415.

101. Walker R: Retention in treatment--indicator or illusion: An essay. Substance Use and Misuse 2009, 44:18-27.

102. Hubbard RL, Craddock SG, Anderson J: Overview of 5-year followup outcomes in the drug abuse treatment outcome studies (DATOS). Journal of Substance Abuse Treatment 2003, 25:125-134.

103. Stark M: Dropping out of substance abuse treatment: a clinically oriented review. Clinical Psychology Review 1992, 12:93-116.

104. Bottlender M, Soyka M: Outpatient alcoholism treatment: Predictors of outcome after 3 years. Drug and Alcohol Dependence 2005, 80:83-89.

105. Moos RH, Moos BS: Long-term influence of duration and intensity of treatment on previously untreated individuals with alcohol use disorders. Addiction 2003, 98:325-337.

106. Miller WR, Wilbourne PL: Mesa Grande: A methodological analysis of clinical trials of treatments for alcohol use disorders. Addiction 2002, 97:265-277.

107. Moyer A, Finney JW, Swearingen CE, Vergun P: Brief interventions for alcohol problems: A meta-analytic review of controlled investigations in treatment-seeking and non-treatment-seeking populations. Addiction 2002, 97:279-292.

108. Kaner EF, Beyer F, Dickinson HO, Pienaar E, Campbell F, Schlesinger C, Heather N, Saunders J, Burnand B: Effectiveness of brief alcohol interventions in primary care populations. Cochrane Database of Systematic Reviews 2007:CD004148.

109. Moos RH: latrogenic effects of psychosocial interventions for substance use disorders: Prevalence, predictors, prevention. Addiction 2005, 100:595-604.

110. Sobell LC, Cunningham JA, Sobell MB: Recovery from alcohol problems with and without treatment: Prevalence in two population surveys. American Journal of Public Health 1996, 86:966-972.

111. Dawson DA, Grant BF, Stinson FS, Chou PS, Huang B, Ruan WJ: Recovery from DSM-IV alcohol dependence: United States, 2001-2002. Addiction 2005, 100:281-292.

112. Joe GW, Simpson DD, Broome KM: Retention and patient engagement models for different treatment modalities in DATOS. Drug and Alcohol Dependence 1999, 57:113-125.

113. Sung $\mathrm{H}$, Belenko S, Feng L: Treatment compliance in the trajectory of treatment progress among offenders. Journal of Substance Abuse Treatment 2001, 20:153-162.

114. Schacht Reisinger $H$, Bush T, Colom M, Agar M, Battjes R: Navigation and engagement: How does one measure success? Journal of Drug Issues 2003, 33:777-800.

115. Sung HE, Belenko S, Feng L, Tabachnick C: Predicting treatment noncompliance among criminal justice-mandated clients: $A$ theoretical and empirical exploration. Journal of Substance Abuse Treatment 2004, 26:315-328.

116. Simpson DD: A conceptual framework for drug treatment process and outcomes. Journal of Substance Abuse Treatment 2004, 27:99-121.

117. Hser YI, Yamaguchi K, Chen J, Anglin MD: Effects of interventions on relapse to narcotics addiction: An event-history analysis. Evaluation Review 1995, 19:123-140.

118. Anglin MD, Hser Yl: Criminal justice and the drug-abusing offender: Policy issues of coerced treatment. Behavioral Sciences and the Law 1991, 9:243-267

119. Simpson DD, Joe GW: A longitudinal evaluation of treatment engagement and recovery stages. Journal of Substance Abuse Treatment 2004, 27:89-97.

120. Hser YI, Grella CE, Hsieh SC, Anglin MD, Brown BS: Prior treatment experience related to process and outcomes in DATOS. Drug and Alcohol Dependence 1999, 57:137-150.

121. Hser YI, Longshore D, Anglin MD: The life course perspective on drug use: A conceptual framework for understanding drug use trajectories. Evaluation Review 2007, 31:515-547.
122. Covington J: Linking treatment to punishment: An evaluation of drug treatment in the criminal justice system. In Informing America's policy on illegal drugs: What we don't know keeps hurting us Edited by: Manski C, Pepper J, Petrie C. Washington, DC: National Academy of Sciences; 2001:349-381.

123. McLellan AT, Lewis DC, O'Brien CP, Kleber HD: Drug dependence, a chronic medical illness: Implications for treatment, insurance, and outcomes evaluation. Journal of the American Medical Association 2000, 284:1689-1695.

124. Gostin LO: Compulsory treatment for drug-dependent persons: Justifications for a public health approach to drug dependency. Milbank Quarterly 1991, 69:561-593.

125. Fagan $\mathrm{R}$ : The use of required treatment for substance abusers. Substance Abuse 1999, 20:249-261.

126. Anglin MD: A social policy analysis of compulsory treatment for opiate dependence. Journal of Drug Issues 1988, 18:

127. Childress JF, Faden RR, Gaare RD, Gostin LO, Kahn J, Bonnie RJ, Kass NE, Mastroianni AC, Moreno JD, Nieburg P: Public health ethics: Mapping the terrain. Journal of Law, Medicine, and Ethics 2002, 30:170-178.

128. Upshur REG: Principles for the justification of public health intervention. Canadian Journal of Public Health 2002, 93:101-103.

doi: 10.1186/1477-7517-7-13

Cite this article as: Urbanoski, Coerced addiction treatment: Client perspectives and the implications of their neglect Harm Reduction Journal 2010, 7:13

\section{Submit your next manuscript to BioMed Central and take full advantage of:}

- Convenient online submission

- Thorough peer review

- No space constraints or color figure charges

- Immediate publication on acceptance

- Inclusion in PubMed, CAS, Scopus and Google Scholar

- Research which is freely available for redistribution 